\title{
Modeled and observed ozone sensitivity to mobile-source emissions in Mexico City
}

\author{
M. Zavala ${ }^{1,2}$, W. Lei ${ }^{1,2}$, M. J. Molina ${ }^{2, *}$, and L. T. Molina ${ }^{1,2}$ \\ ${ }^{1}$ Molina Center for Energy and the Environment, La Jolla, California, USA \\ ${ }^{2}$ Massachusetts Institute of Technology, Cambridge, Massachusetts, USA \\ *now at: Department of Chemistry and Biochemistry, University of California, San Diego, California, USA
}

Received: 2 July 2008 - Published in Atmos. Chem. Phys. Discuss.: 6 August 2008

Revised: 17 November 2008 - Accepted: 17 November 2008 - Published: 7 January 2009

\begin{abstract}
The emission characteristics of mobile sources in the Mexico City Metropolitan Area (MCMA) have changed significantly over the past few decades in response to emission control policies, advancements in vehicle technologies and improvements in fuel quality, among others. Along with these changes, concurrent non-linear changes in photochemical levels and criteria pollutants have been observed, providing a unique opportunity to understand the effects of perturbations of mobile emission levels on the photochemistry in the region using observational and modeling approaches. The observed historical trends of ozone $\left(\mathrm{O}_{3}\right)$, carbon monoxide $(\mathrm{CO})$ and nitrogen oxides $\left(\mathrm{NO}_{\mathrm{x}}\right)$ suggest that ozone production in the MCMA has changed from a low to a high VOC-sensitive regime over a period of 20 years. Comparison of the historical emission trends of $\mathrm{CO}, \mathrm{NO}_{\mathrm{x}}$ and hydrocarbons derived from mobile-source emission studies in the MCMA from 1991 to 2006 with the trends of the concentrations of $\mathrm{CO}, \mathrm{NO}_{\mathrm{x}}$, and the $\mathrm{CO} / \mathrm{NO}_{\mathrm{x}}$ ratio during peak traffic hours also indicates that fuel-based fleet average emission factors have significantly decreased for $\mathrm{CO}$ and VOCs during this period whereas $\mathrm{NO}_{\mathrm{x}}$ emission factors do not show any strong trend, effectively reducing the ambient $\mathrm{VOC} / \mathrm{NO}_{\mathrm{x}}$ ratio.
\end{abstract}

This study presents the results of model analyses on the sensitivity of the observed ozone levels to the estimated historical changes in its precursors. The model sensitivity analyses used a well-validated base case simulation of a high pollution episode in the MCMA with the mathematical Decoupled Direct Method (DDM) and the standard Brute Force Method (BFM) in the 3-D CAMx chemical transport model.

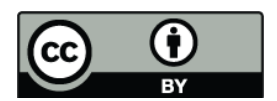

Correspondence to: M. Zavala (miguelz@mce2.org)
The model reproduces adequately the observed historical trends and current photochemical levels. Comparison of the BFM and the DDM sensitivity techniques indicates that the model yields ozone values that increase linearly with $\mathrm{NO}_{\mathrm{x}}$ emission reductions and decrease linearly with VOC emission reductions only up to $30 \%$ from the base case. We further performed emissions perturbations from the gasoline fleet, diesel fleet, all mobile (gasoline plus diesel) and all emission sources (anthropogenic plus biogenic). The results suggest that although large ozone reductions obtained in the past were from changes in emissions from gasoline vehicles, currently significant benefits could be achieved with additional emission control policies directed to regulation of VOC emissions from diesel and area sources that are high emitters of alkenes, aromatics and aldehydes.

\section{Introduction}

Emission-based air quality control strategies in an urban area are typically directed towards the regulation of nitrogen oxides $\left(\mathrm{NO}_{x}\right)$ and/or volatile organic compounds (VOCs) from various emission sources (NRC, 1991). In many large urban areas, including the Mexico City Metropolitan Area (MCMA), mobile sources are responsible for most of the $\mathrm{NO}_{\mathrm{x}}$ and VOCs produced (Molina and Molina, 2002). Emitted $\mathrm{NO}_{\mathrm{x}}$ and VOCs are transformed in the presence of sunlight to produce ozone, nitric acid and other oxidants in a complex series of chemical reactions that occur along the transport of air masses (e.g., Seinfeld and Pandis, 1998). Photochemical reactions also generate secondary organic, nitrate and sulfate particulate matter (PM). Regional transport can move air pollutants outside of the urban areas where

Published by Copernicus Publications on behalf of the European Geosciences Union. 
they are generated. In addition to the impacts on $\mathrm{NO}_{\mathrm{x}}$ and VOCs, mobile source emissions are also significant contributors to toxic species. Therefore, substantial benefits for human health, ecosystem vitality and climate can be achieved by policies that result in reduced mobile-source emissions.

Past and recent field campaigns held in the MCMA have shown a strong influence of mobile-source emissions on the photochemical pollutant levels within the basin (Molina et al., 2007). Moreover, the emission characteristics of mobile sources in the MCMA have changed significantly over the course of the past few decades in response to emission control policies: advancements in emission control technologies, improvements in fuel quality, and vehicle inspection and maintenance programs (Molina and Molina, 2004). Fleet turnover with introduction of better technologies in new vehicles has reduced emissions from individual gasoline fuelled vehicles. Along with these changes, concurrent non-linear changes in photochemical pollutant levels as well as PM, toxic and criteria pollutants have been observed (Molina et al., 2007). These pollutant changes indicate that the ambient $\mathrm{VOC} / \mathrm{NO}_{\mathrm{x}}$ ratio in the city has been modified, which should impact future control policy emphases.

The large number of measurements of both mobile-source emissions and air pollutant levels during the past two decades in the MCMA provides an opportunity to understand the effects of perturbations of mobile emission levels on the photochemistry in this region. By comparing concurrent changes in photochemical levels to mobile-source emission changes, it is possible to investigate this "observed" sensitivity and compare it to "modeled" sensitivity tests using air quality models.

To carry out the model sensitivity analyses we selected a base case simulation of a high pollution episode on 1316 of April during the MCMA-2003 Campaign (Molina et al., 2007) using the 3-D CAMx chemical transport model (ENVIRON, 2006), which simulates the emission, transport, chemistry, and deposition processes of pollutants in the troposphere. The evaluation of the model performance is provided in Lei et al. (2007). The sensitivity studies that estimate model responses to changes in the model inputs were carried out using the mathematical Decoupled Direct Method (DDM) and the results are validated using the standard Brute Force Method (BFM).

The BFM is conceptually the simplest sensitivity analysis method since each model input parameter is perturbed separately and the model output is evaluated for each control run. The change in model output is compared between the control run and the base case; this process is repeated for each input parameter investigated. In air quality modeling (AQM) applications this process can rapidly become time consuming and computationally expensive. Besides being computationally inefficient for most AQM applications, the magnitude and direction of the sensitivities estimated with the BFM depend upon the magnitude of the perturbation if the model response is nonlinear. In addition, for small model input perturbations the estimated sensitivities may contain significant levels of uncertainties introduced by numerical noise. Nevertheless, since the method is in principle applicable to any model input parameter and the results are relatively easy to interpret, the BFM is often used for the validation of more complex mathematical-based sensitivity analyses (Hamby, 1994).

The DDM was first used in the calculation of sensitivity coefficients in a three-dimensional air quality model (the Urban Airshed Model, UAM) by Alan Dunker in the early 1980s (Dunker, 1981). The DDM was also applied to the California/Carnegie Institute of Technology (CIT) airshed model in an application termed DDM-3-D (Yang et al., 1997). More recently, the implementation of the DDM in CAMx to calculate first-order sensitivities with respect to emissions and initial and boundary concentrations was reported by Dunker et al. (2002), who compared the accuracy of the DDM sensitivity analyses with those estimated using the BFM. The DDM was found to be highly accurate for calculating the sensitivity of the 3-D-model for perturbations up to $40 \%$ in reductions from the base case. The DDM has been used also in the CMAQ model to estimate PM sensitivities (Napelenok et al., 2006) and for PM source apportionment of linear systems (Yarwood et al., 2004).

In this paper we investigate the observed and modeled effects on the photochemical pollutant levels from perturbations of mobile-source emissions. We first describe the historically observed effects on ozone, $\mathrm{CO}$ and $\mathrm{NO}_{\mathrm{x}}$ trends in the urban area using data from the local ambient monitoring network. We also compare the historical trends of $\mathrm{CO}, \mathrm{NO}_{\mathrm{x}}$ and hydrocarbons (HCs) derived from mobile-source emissions measurements in the MCMA from 1991 to 2006 with pollutant trends of hourly data of $\mathrm{CO}, \mathrm{NO}_{\mathrm{x}}$, and the $\mathrm{CO} / \mathrm{NO}_{\mathrm{x}}$ ratio from the monitoring network during peak traffic hours. We use this approach to estimate the magnitude of the historical perturbations in mobile-source emissions in the urban area. The observed effects are the basis for evaluating the sensitivity analyses obtained from the DDM and BFM modeling techniques.

\section{Observed sensitivity effects}

To investigate the observed effects on the photochemical levels in the urban area from perturbations of mobile-source emissions, we have analyzed the concurrent changes in ozone, $\mathrm{CO}$ and $\mathrm{NO}_{\mathrm{x}}$ using a 21-year (1986-2006) data set from the MCMA ambient air quality monitoring network, RAMA (for Red Automatica de Monitoreo Atmosferico), which has continuously measured criteria pollutants since 1986. The network consists of 34 stations located in the metropolitan area and is maintained by the Environment Secretary of the Government of the Federal District. The data is reported hourly and is publicly available at http://www.sma. df.gob.mx/simat/. 

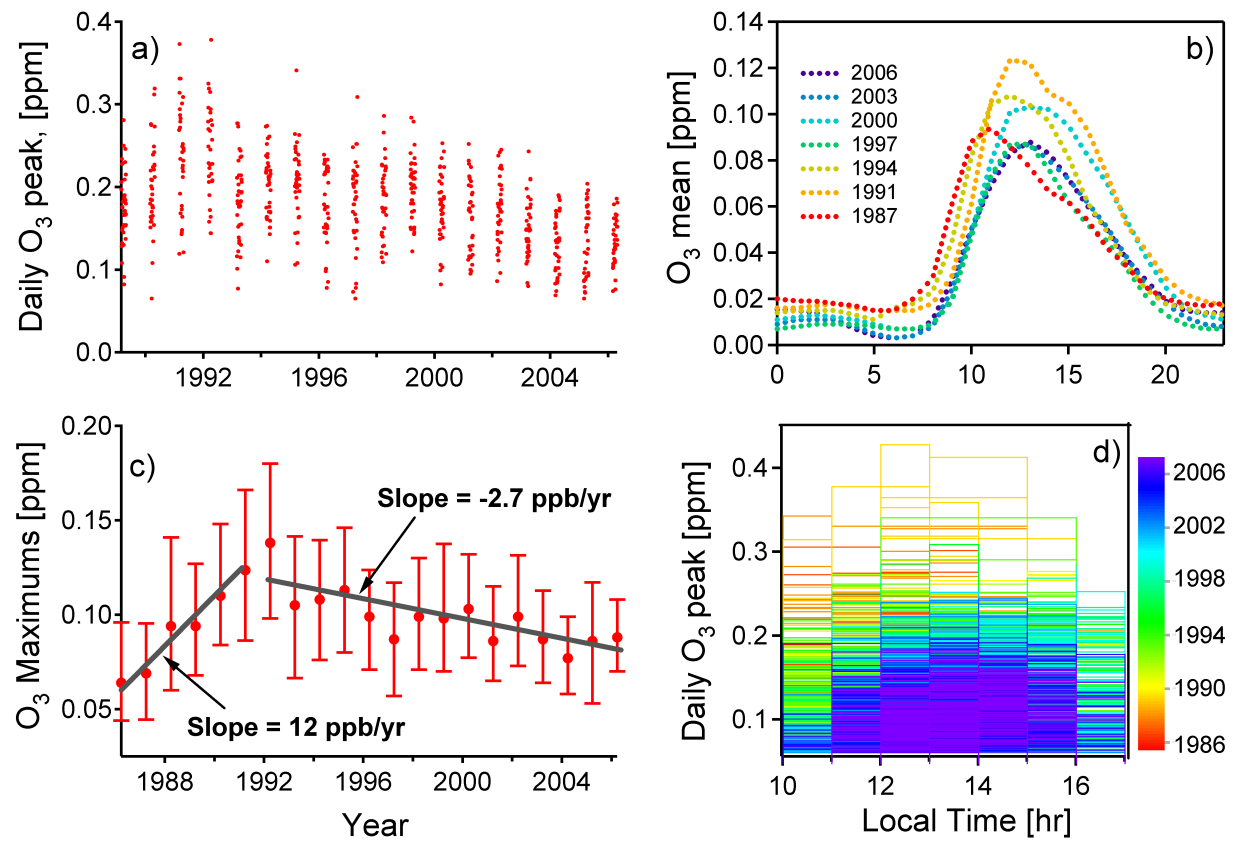

Fig. 1. (a) City-wide daily ozone peak, (b) daily mean ozone profile, (c) 25 th, 50th, and 75 th percentiles of daily ozone maximums, (d) daily ozone peak vs. local time occurrence of the peak. See text for data filtering procedures.

We have included all hourly data with a valid reading for each day only from March to April. By doing this, we minimize the effects of inter-annual seasonal variability of key meteorological parameters on ozone formation in our analysis. These months, which typically register high pollution levels, correspond also to the periods in which the MCMA2003 (Molina et al., 2007) and MCMA-2006/MILAGRO (Molina et al., 2008) field campaigns were carried out. To minimize data noise induced by the "weekend effect" (e.g., Altshuler et al., 1995) on the analysis of the ozone trends, we have excluded all data from Saturdays and Sundays. In addition, we have excluded the days for the Holy Week and all other major holidays when traffic patterns are different and mobile emissions are reduced.

\subsection{Ozone trends}

We focus our analysis on the trends of the daily ozone peak (that is, the city-wide maximum of all the daily ozone maximums over all the stations in a given day), the daily ozone maximums (the maximum ozone concentration for each station per day), and the ozone mean daily profile (averaged over all stations). Interesting trends on the magnitude, temporal and spatial allocation of ozone are clearly discernible from the 21-year data. Figure 1a shows that the peak ozone levels have significantly decreased (by more than $100 \mathrm{ppb}$ ) whereas a moderate decrease in the mean and maximum ozone diurnal levels has occurred. These changes are concurrent with a decrease in the spatial variability of the ozone fields (that is, the differences between the ozone levels measured at all the stations), mainly due to smaller ozone peaks in recent years.

The results indicate significant changes in the diurnal profiles of ozone, particularly before and after 1992. Figure $1 \mathrm{~b}$ shows that mean ozone concentrations initially increased from 1986 to 1991 and then started a steady downward trend. In general, the night-time ozone levels are lower in recent years and the levels in the early hours before sunrise have decreased also. Overall, the mean ozone concentrations during the peak photochemical periods have reduced by about $25 \mathrm{ppb}$ since 1991. As shown later, this is probably linked to diurnal changes in $\mathrm{NO}_{\mathrm{x}}$ emissions. Figure $1 \mathrm{c}$ also indicates that a rapid increase in maximum concentrations occurred during the first 5 years of data with an alarming rate of $12 \pm 1.3 \mathrm{ppb} / \mathrm{year}$, followed by a steady decrease of about $2.7 \pm 0.5 \mathrm{ppb} / \mathrm{yr}$ since 1992 . As will be discussed later, these changes are strongly related to changes in anthropogenic emissions, with mobile sources playing a significant role in both the increase and decrease. The observed inter-annual variability of the maximum ozone concentrations trends has not significantly changed (Fig. 1b), indicating that high concentrations are still common in the city.

Figure $1 \mathrm{~d}$ shows that the reduction of the daily ozone peak levels has been accompanied with a "delay" in its local time occurrence by 2 to $3 \mathrm{~h}$ with respect to earlier years. This effect has been observed also in maximum ozone concentrations for all stations with a delay from about 11:00 a.m. in the early years to about 01:00 p.m. in recent years. Because 

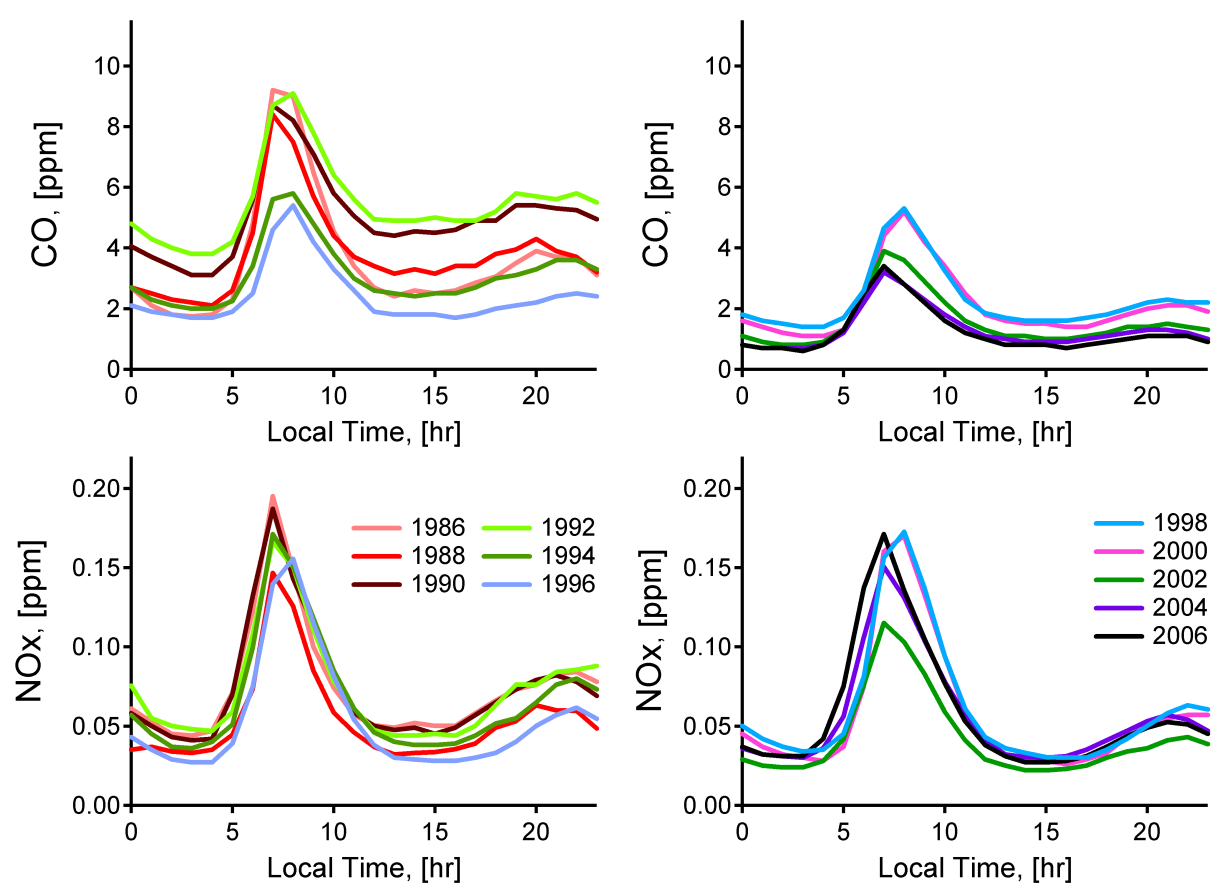

Fig. 2. Daily mean $\mathrm{CO}$ and $\mathrm{NO}_{\mathrm{x}}$ profiles. See text for data filtering procedures.

the data have been filtered to minimize seasonal effects, this delaying effect on the ozone-peak timing is most probably caused by changes in ozone precursor levels, rather than to changes in meteorological conditions.

As a consequence of the observed time delay in high ozone concentrations, the spatial allocation of the peak ozone concentrations may change significantly since air masses containing the city emissions may travel longer distances by the time the ozone peak occurs. The delay suggests that some reductions in high ozone levels in fact may not be as large as indicated by the monitoring network because the network could be "blinded" to the actual (basin-wide) daily ozone peak, which may be occurring downwind at places where there are no monitoring stations. This idea is explored further in the modeling sensitivity analysis section below.

\section{$2.2 \mathrm{CO}$ and $\mathrm{NO}_{\mathrm{x}}$ trends}

$\mathrm{CO}$ and $\mathrm{NO}_{\mathrm{x}}$ levels are dominated by anthropogenic emission sources in urban areas. In Mexico City, mobile sources are the predominant sources accounting directly for about $99 \%$ and $84 \%$ of total $\mathrm{CO}$ and $\mathrm{NO}_{\mathrm{x}}$ emissions respectively (CAM, 2006). Therefore, the observed variability of $\mathrm{CO}$ and $\mathrm{NO}_{\mathrm{x}}$ levels is likely to be significantly influenced by changes in the emission characteristics of mobile sources.

Figure 2 shows that $\mathrm{CO}$ mean concentrations have decreased significantly whereas mean $\mathrm{NO}_{\mathrm{x}}$ concentrations have stayed about the same over time. The spatial variability of the CO concentration fields (as indicated by the changes between the 90th and 10th percentiles, not shown) has also been reduced, but $\mathrm{NO}_{\mathrm{x}}$ variability has not. Similarly, large reductions are observed for the high $\mathrm{CO}$ concentrations in early morning hours whereas the corresponding high $\mathrm{NO}_{\mathrm{x}}$ concentrations have persisted. The $\mathrm{CO}$ mean concentration profiles in Fig. 2 show a much larger relative reduction than the reductions in mean ozone concentrations shown in Fig. 1, because ozone is a secondary pollutant and is not linearly dependent on its primary precursors. The variability of the mean $\mathrm{NO}_{\mathrm{x}}$ concentration profiles in recent years is similar to the early years. This suggests that the balance between sources and sinks of $\mathrm{NO}_{\mathrm{x}}$ has not changed significantly over this period.

Important changes in the temporal emission patterns of mobile emissions in the city appear to have happened. Figure 3 shows the normalized temporal profiles for mean $\mathrm{CO}$ in which each hourly value represents the percentage contribution to the total accumulated daily concentration. The figure shows a negative shift in time of 1 to $2 \mathrm{~h}$ of the median concentration patterns during the early morning hours. The same effect is observed in the corresponding analysis of $\mathrm{NO}_{x}$ levels (not shown). Due to the filtering criteria used we expect similar mixing characteristics over these years, thus this effect is most likely due to changes in the temporal emission patterns in the city. One possible explanation is that, as congestion increases due to large increase of vehicle fleet size with little changes in road infrastructure, residents need 


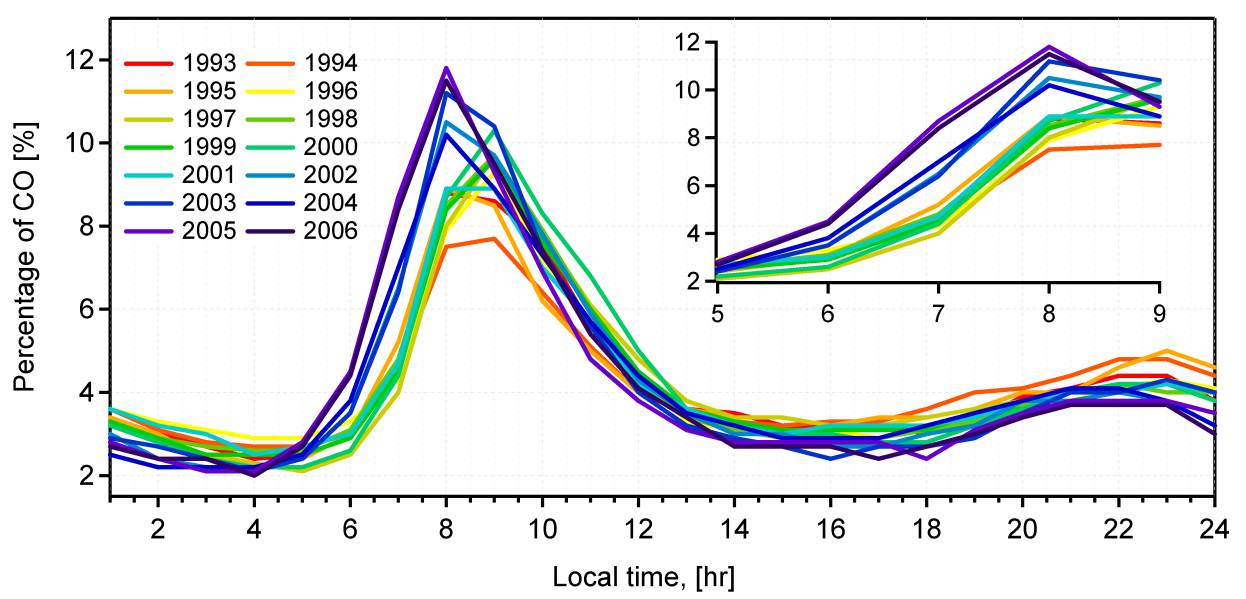

Fig. 3. Mean CO profiles as hourly-percentage contribution to total daily concentrations.

to leave home earlier to arrive to work on time. Fresh $\mathrm{NO}_{\mathrm{x}}$ emissions would remove ozone carried over from night time chemistry and transport, in agreement with the decrease in ozone levels observed in Fig. 1b at this period. The massive injection of emissions in "dark" conditions into a shallow boundary layer has profound implications on the chemistry in subsequent hours.

\subsection{Estimating historical changes in mobile-source emis-} sions

Mobile-source emissions in the MCMA have been studied since the early 1990's using several measurement techniques including remote sensing (Bishop et al., 1997; Schifter et al., 2003a; GDF, 2006), dynamometer studies (Schifter et al., 2003b), tunnel studies (Mugica et al., 1998), and more recently in 2003 and 2006 with on-road sampling techniques using a mobile laboratory (Zavala et al., 2006). Fleet-average mobile-source emission estimates were also obtained in 2003 using long-path measurement techniques by analyzing the build-up of emitted species $/ \mathrm{CO}_{2}$ ratios during early morning rush hours (Volkamer et al., 2005). Cross-validation and inter-comparison of these techniques are intrinsically difficult to perform due to differences in sampling times and frequencies, pollutant measurements instrumentation, sampling size and analysis assumptions for each measurement type. Nevertheless, since these techniques have been applied in the MCMA at different times in the past two decades, it is worthwhile to make what comparisons are possible.

Figures $4 \mathrm{a}$ and $\mathrm{c}$ show the emission factors of $\mathrm{CO}, \mathrm{HCs}$, and $\mathrm{NO}_{\mathrm{x}}$ measured in the MCMA during the past two decades. In this figure, the units reported from different studies were homogenized to fuel-based estimates assuming a fuel density of $0.75 \mathrm{~kg} / \mathrm{l}$, a fuel economy of $10 \mathrm{~km} / \mathrm{l}$, and 70.3 moles of $\mathrm{C}$ per $\mathrm{kg}$ of fuel for gasoline. The results indicate that fleet average emission factors have drastically de- creased for $\mathrm{CO}$ and $\mathrm{HC}$ over the past two decades (Fig. 4a), whereas $\mathrm{NO}_{\mathrm{x}}$ emission factors have not shown any strong trend (Fig. 4c), keeping in mind that the vehicle fleet has increased greatly during these years. Figure $4 \mathrm{~b}$ also shows that the renewal rate of the vehicle fleet (the difference between the cumulative vehicle sales and the number of vehicles between two given periods) has significantly increased in recent years and that gasoline sales have increased almost linearly. The reducing variability bars of Fig. 4a indicate that the age of the fleet is homogenizing faster: not only are many new vehicles being added to the fleet, but older vehicles appear to be rapidly taken out of the fleet. The observed reduction of $\mathrm{CO}$ and $\mathrm{HC}$ variability is, in turn, in good agreement with the observed downward trends in variability for ambient $\mathrm{CO}$ concentration profiles shown in Fig. 2. The effect of greater reductions in $\mathrm{CO}$ and $\mathrm{HC}$ than in $\mathrm{NO}_{\mathrm{x}}$ emissions is not surprising. Gasoline cars and light trucks are the major mobile sources for $\mathrm{CO}$ and $\mathrm{HC}$, while almost half of the mobilesource $\mathrm{NO}_{\mathrm{x}}$ emissions are from diesel vehicles. The introduction of improved gasoline emission control devices over this time period would affect total mobile-source $\mathrm{CO}$ and $\mathrm{HC}$ more than $\mathrm{NO}_{\mathrm{x}}$.

Figure $4 \mathrm{c}$ indicates that there is no strong trend for the $\mathrm{NO}_{\mathrm{x}}$ emission factor and that a larger variability is observed for $\mathrm{NO}_{\mathrm{x}}$ than for $\mathrm{CO}$ and $\mathrm{HCs}$ emission factors. Unfortunately, the earliest fleet-average $\mathrm{NO}_{\mathrm{x}}$ emission measurements were performed in the year 2000; therefore there are simply not sufficient measurements in this time span to observe any trend in $\mathrm{NO}_{\mathrm{x}}$. In order to obtain a better estimate of changes in $\mathrm{NO}_{\mathrm{x}}$ emissions over the past two decades, we used a second, indirect, approach by analyzing changes in the 06:00 to 09:00 a.m. values of the $\mathrm{CO} / \mathrm{NO}_{\mathrm{x}}$ ratio measured by the ambient monitoring stations in the city. Mobile sources are the major emission source during the 06:00 to 09:00 a.m. time period because high emissions levels are generated by rushhour traffic (e.g. Zavala et al., 2006) and they are not rapidly 

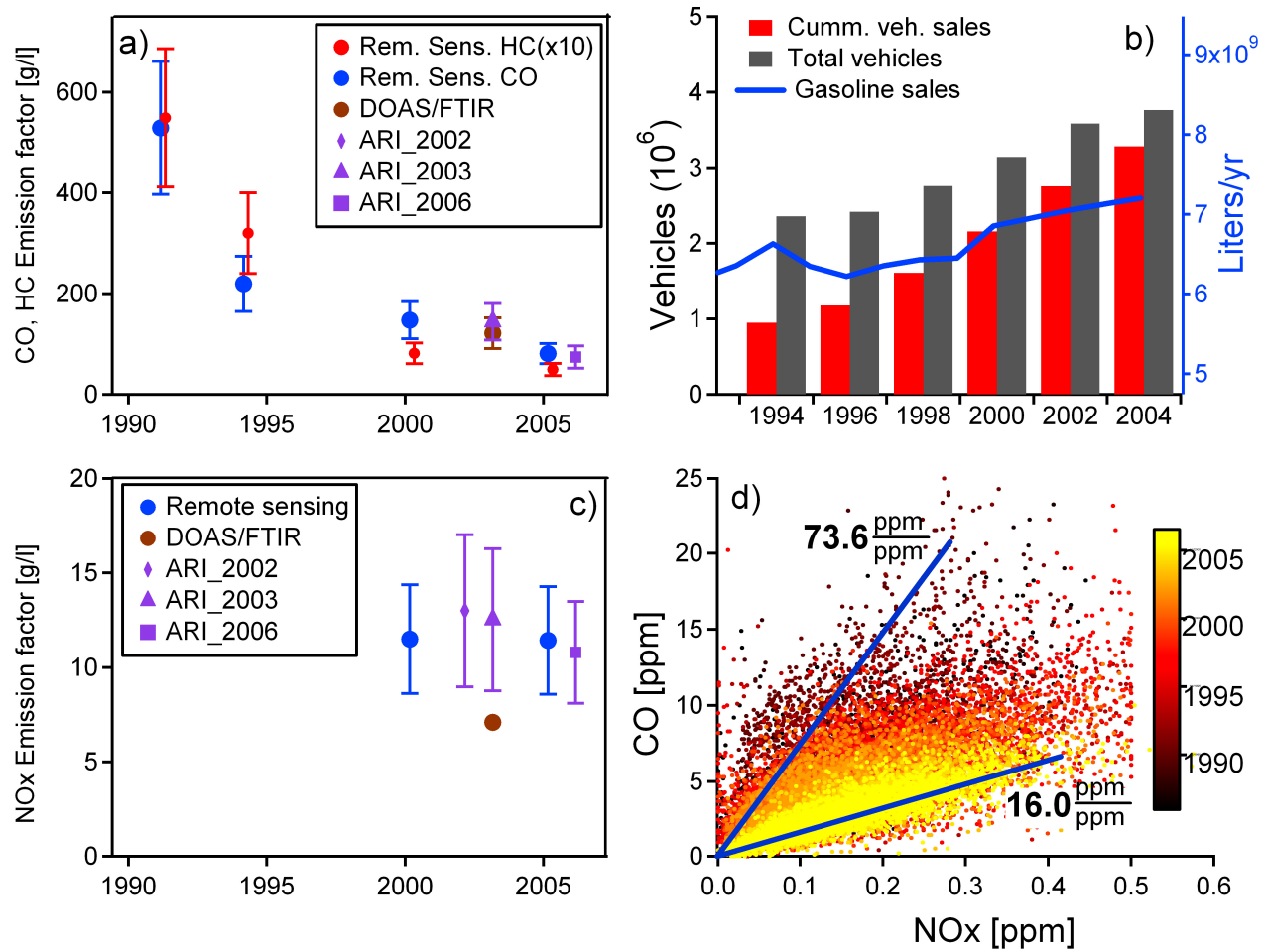

Fig. 4. (a) Trends in emission factors for $\mathrm{CO}$ and hydrocarbons (HC, in propane equivalents, multiplied by 10); (b) cumulative vehicle sales and number of vehicles per year; (c) trends in emission factors for $\mathrm{NO}_{\mathrm{x}}$; and (d) Annual trends of $\mathrm{CO} / \mathrm{NO}_{\mathrm{x}}$ between 06:00 to 09:00 a.m. Data from crossroad remote sensing studies (GDF, 2006), long-path DOAS/FTIR (Volkamer et al., 2005), and on-road sampling from the Aerodyne mobile lab in 2002, 2003 and 2006 (Zavala et al., 2006).

dispersed at this time because the mixing height is still at a developing stage (Shaw et al., 2007). Furthermore, the use of the ratio of concurrent $\mathrm{CO}$ to $\mathrm{NO}_{\mathrm{x}}$ concentrations accounts for dilution effects - due to vertical mixing and transport during the analysis. Because of the filtering criteria applied, the $06: 00$ to $09: 00$ a.m. $\mathrm{CO} / \mathrm{NO}_{\mathrm{x}}$ ratio trend is more likely to be the result of long-term variability of mobile sources. Also, at this time of the day the pool of emitted $\mathrm{NO}_{\mathrm{x}}$ molecules is not yet significantly catalytically active (as compared to the rest of the diurnal period) in the photochemical cycle because $\mathrm{NO}_{2}$ photolysis peaks around noon. The observed $\mathrm{NO}_{\mathrm{x}}$ trend has a stronger signal of its primary component (NO) during this period (the measured $\mathrm{NO}_{2} / \mathrm{NO}_{\mathrm{x}}$ ratio is at its lowest, not shown).

A significant decrease in the early morning ambient $\mathrm{CO} / \mathrm{NO}_{\mathrm{x}}$ ratio of about 4.6 is observed in Fig. $4 \mathrm{~d}$, which also shows that the decrease has been driven by reductions in CO. These results are similar to those found by Stephens et al. (2008), who examined day-of-the-week patterns of air pollutants in the MCMA during the same two-decade period. The concurrent reduction in the magnitude and variability of ambient $\mathrm{CO}$ concentrations with the trends of $\mathrm{CO}$ and $\mathrm{HC}$ mobile emission factors, the early morning $\mathrm{CO} / \mathrm{NO}_{\mathrm{x}}$ ratio, as well as the high percentage of mobile-source emissions in the emission inventory, indicate that emissions from mobile sources, rather than point and area sources, are largely responsible for the observed downward concentration trends.

\section{Model sensitivity}

\subsection{Base case simulation}

The formulation and evaluation of the model's performance for the 4-day base case simulation period (13-16 April 2003) used here are based on the findings of Lei et al. (2007). The 3-D CAMx model (Environ, 2003) is driven by hourly meteorological output fields from the Penn State/National Center for Atmospheric Research (PSU/NCAR) Mesoscale Modeling System (MM5) (Grell et al., 1995) configured to three one-way nesting with grid resolutions of 36,12 and $3 \mathrm{~km}$ and 23 sigma levels in the vertical (de Foy et al., 2006). The model was run using the SAPRC99 gas phase chemical mechanism (Carter, 2000) and the photolysis rate frequencies for clear sky were pre-computed with the Tropospheric Ultraviolet and Visible radiation model (TUV) (Madronich and Flocke, 1998). The emission input fields for the simulation period (April 2003) were constructed by interpolating the 2002 and 2004 official emissions inventories (EI) 

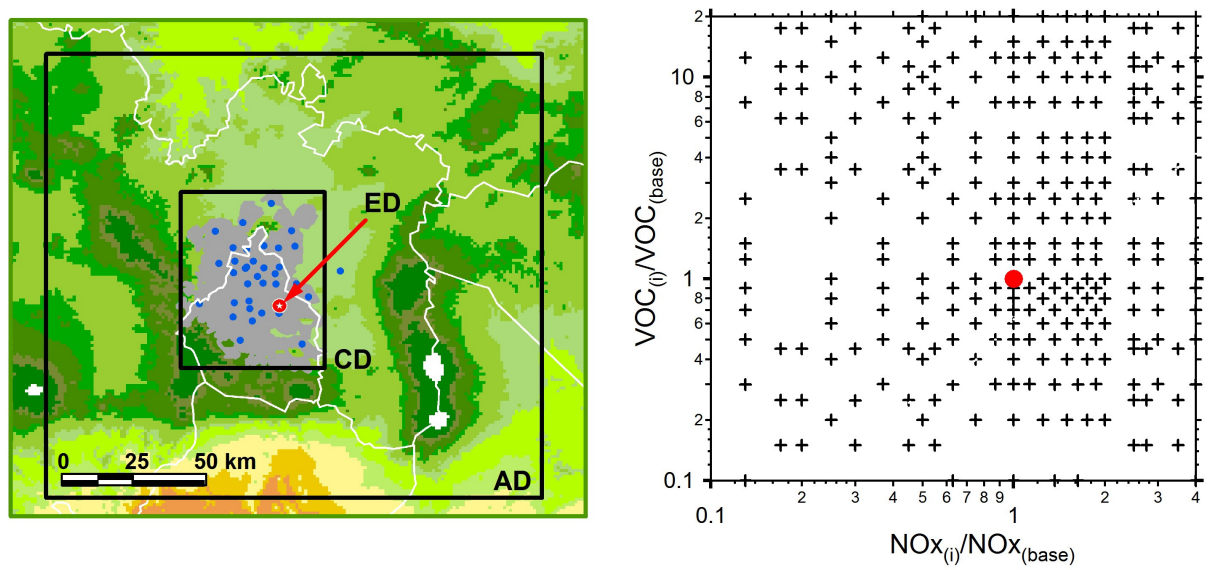

Fig. 5. Left panel shows the domains for which isopleths are constructed: domain-wide (AD, biggest square), city-domain (CD, surrounding the urban area), and the measuring supersite (ED, red symbol). Blue dots show the location of the monitoring stations and white lines show the political boundaries of the region. Right panel shows emission perturbation schemes performed using the BFM method for the April 15, 2003 base case (red dot).

(CAM, 2006). A summary of the total basin-wide initial emissions by source category and pollutant type is given in Table 1. Interpolated total annually emitted masses of VOCs, $\mathrm{CO}$ and $\mathrm{NO}_{\mathrm{x}}$ were distributed across mobile-, point- and area- source emissions categories and were transformed into spatially and temporally resolved and chemically speciated emission fields.

The performance of the MM5 model for simulating the meteorological patterns of the selected period has been described in detail elsewhere (de Foy et al., 2006. See also other MM5 modeling studies of Mexico City, e.g., Jazcilevich et al., 2005). The main features of the Mexico City basin flow are well represented by the model including the northerly flow from the Mexican Plateau during the day, upslope flows on the basin edges and the southerly gap flow from the southeast passage in the late afternoon and early evening. Weak synoptic forcing leads to surface winds that are weak and variable and are particularly challenging to model. The performance of CAMx was evaluated by comparing near surface ozone, $\mathrm{NO}_{\mathrm{y}}$ and $\mathrm{CO}$ concentrations with data from the RAMA monitoring network and the extensive VOC data sets obtained during the MCMA-2003 campaign (Molina et al., 2007). Simulated $\mathrm{O}_{3}, \mathrm{CO}$ and $\mathrm{NO}_{\mathrm{y}}$ agree particularly well with the measurements from the monitoring network within the modeled and experimental variability, and there are no systematic biases between modeled and observed daytime $\mathrm{CO}$ and $\mathrm{NO}_{\mathrm{y}}$ (Lei et al., 2007, 2008). The results give us confidence in the model performance and in the accuracy of the emissions of $\mathrm{CO}$ and $\mathrm{NO}_{\mathrm{x}}$ used in the model. As described in Lei et al. (2007), the predicted concentrations of alkenes and speciated alkanes agree very well with measured concentrations from canister samples. Similarly, there is good agreement between predicted and observed concentrations of aromatics and formaldehyde, particularly for 15
Table 1. Annual base case emissions inventory used in this study.

\begin{tabular}{llllll}
\hline Emission source & $\mathrm{CO}$ & $\mathrm{NMHC}$ & $\mathrm{NO}_{\mathrm{x}}$ & $\mathrm{SO}_{2}$ & $\mathrm{NH}_{3}$ \\
\hline & $(\%)$ & $(\%)$ & $(\%)$ & $(\%)$ & $(\%)$ \\
Gasoline fleet & 56 & 19 & 36 & 32 & 15 \\
Diesel fleet & 23 & 8 & 33 & 14 & 2 \\
Taxis & 8 & 3 & 7 & 6 & 3 \\
Public transport & 13 & 4 & 8 & 3 & 1 \\
All mobile* & 99 & 34 & 84 & 55 & 21 \\
Electricity generation & $<1$ & $<1$ & 6 & $<1$ & $<1$ \\
Other Industries* & $<1$ & 17 & 5 & 45 & $<1$ \\
All Indus. sources & $<1$ & 17 & 11 & 45 & 1 \\
Residential cooking & $<1$ & $<1$ & 2 & $<1$ & $<1$ \\
Airports & $<1$ & $<1$ & 1 & $<1$ & $<1$ \\
Solvents & 0 & 14 & 0 & 0 & 0 \\
LPG leakage & 0 & 12 & 0 & 0 & 0 \\
Other area* & $<1$ & 20 & 1 & $<1$ & 78 \\
All area sources & $<1$ & 46 & 4 & $<1$ & 78 \\
Biogenic & 0 & 3 & $<1$ & 0 & 0 \\
Total in ktons & 1865 & 902 & 181 & 8 & 17 \\
\hline
\end{tabular}

Values are rounded to the nearest integer.

* The official 2004 EI (CAM, 2006) considers 51 emission source categories: 10 for mobile, 10 for industrial, 30 for area sources and 1 for biogenic sources. These categories are lumped here for simplicity of illustration.

April with no systematic bias. We have selected the April 15 th simulation event as our base case for further sensitivity analyses because of the good performance of the model in simulating observed meteorological parameters and reproducing observed ozone concentrations simultaneously with measured VOCs, $\mathrm{CO}$ and $\mathrm{NO}_{\mathrm{x}}$ levels. 


\subsection{Brute force sensitivity method}

We analyze the sensitivity of the model to perturbations of VOC and $\mathrm{NO}_{\mathrm{x}}$ emissions from the gasoline fleet, diesel fleet, all mobile (gasoline plus diesel) and all emission sources (anthropogenic plus biogenic). In Fig. 5 (right panel) each cross represents a model control run with a given perturbation in emissions $\left(\mathrm{VOC}_{(i)}, \mathrm{NO}_{x(i)}\right)$ to the base case $\left(\mathrm{VOC}_{(\text {base })}\right.$, $\mathrm{NO}_{x \text { (base) }}$ ). To further investigate the spatial response of the model's sensitivity we have analyzed the changes of ozone concentrations with respect to the three spatial domains indicated in Fig. 5: AD refers to all cells of the model domain, $\mathrm{CD}$ refers to the cells corresponding only to the urban area, and ED corresponds to the cell containing the supersite location during the MCMA-2003 campaign. In addition, we have also analyzed the changes of the position and the occurrence of the local timing of the ozone peak as a result of perturbations in emissions. Figures 6 and 7 show the corresponding isopleths for the average and peak ozone concentrations along with the resulting changes in the position and local timing of the ozone peak.

The shape of the peak and average concentration isopleths are quite similar for each corresponding emission source category, indicating that the direction of the sensitivity of the model is similar for both the ozone peak and average concentrations to the perturbations of a given emission source. However, the magnitudes of the relative changes for the peak and average ozone concentrations are significantly different. As an illustration, for a perturbation $\operatorname{VOC}_{(i)} / \mathrm{VOC}_{(\text {base })}=7$ and $\mathrm{NO}_{\mathrm{x}(i)} / \mathrm{NO}_{\mathrm{x} \text { (base) }}=1.25$ of the gasoline fleet emissions, the domain-wide peak ozone concentrations increase more than $120 \mathrm{ppb}$ with respect to the base case. For the same emission perturbation, the city-wide ozone diurnal average concentrations increase only by about $30 \mathrm{ppb}$. Despite the large sensitivity for the ozone peak concentrations in the AD domain, the magnitude of the changes of the diurnal average concentrations in the AD domain is much smaller than the corresponding changes in the city wide (CD) domain. This is because in the $\mathrm{AD}$ domain, that contains many non-urban areas, there is a larger number of cells with relatively low ozone concentrations, thus significantly biasing the spatial averaging of ozone concentrations.

Although directionally equal, the sensitivity of the model is not linearly additive: the sensitivity of the model to changes in all mobile emissions is not equal to the sum of the individual sensitivities to perturbations in gasoline and diesel emissions. This is because these source categories have different $\mathrm{VOC} / \mathrm{NO}_{\mathrm{x}}$ emission ratios and therefore contribute differently to the propagation of radicals in the ozone formation process. For example, isopleths obtained from the perturbations in the diesel fleet emissions show a predominant $\mathrm{NO}_{\mathrm{x}}$ sensitive regime since these sources contribute strongly to $\mathrm{NO}_{\mathrm{x}}$ levels. The model also predicts sensitivities three to four times higher with respect to the ozone peak in the city than the average concentrations when perturbing mobile emissions. The sensitivity of the model is in general higher for perturbations from all sources than from mobile sources alone.

The longitudinal $\left(\mathrm{x}_{(i)}\right)$ and latitudinal $\left(\mathrm{y}_{(i)}\right)$ changes for the position of the ozone peak were estimated using the difference in the grid cell index (where the ozone peak registers) between a control run and the base case $\left(\mathrm{x}_{(i)}-\mathrm{x}_{(\text {base })}\right.$ and $\left.\mathrm{y}_{(i)}-\mathrm{y}_{\text {(base) }}\right)$ multiplied by the length of the cell $(3 \mathrm{~km})$. Thus, changes in the position of the ozone peak were estimated as the difference between the cell locations of the ozone peak of the control run and the base case. Similarly, changes in the local timing occurrence of the ozone peak were estimated using the difference in the hours of the occurrence of the local ozone peak for a control run and the local timing of the ozone peak for the base case. Figure 7 indicates that the model reproduces the observed lag in the local timing occurrence of the ozone peak (see Fig. 1d) by about $2 \mathrm{~h}$ with respect to a past VOC-rich scenario. In addition to the observed changes in ozone concentrations, the model reproduces the observed temporal delay in ozone peak formation. Nevertheless, although the model reproduces the time delay effect, clearly the changes in the geographical allocation of the ozone peak are only illustrative because we are limited to one meteorological scenario.

\subsection{DDM sensitivity}

The detailed mathematical basis for the implementation of the DDM in CAMx is presented in detail elsewhere (e.g., Dunker et al., 2002). Briefly, the DDM calculates the sensitivity coefficient, $S_{i}(x, t)$, defined as:

$S_{i}=\frac{\partial_{c}}{\partial \lambda_{i}}$

with respect to the scalar parameter $\lambda_{i}$ by approximating the output concentration variable $c$ with a Taylor series expanded around the base case $\lambda_{0}$. As the magnitude of the input perturbation approaches zero, the output response will become dominated by the first-order sensitivity element:

$c\left(x, t ; \lambda_{i}\right)=c\left(x, t ; \lambda_{0}\right)+\lambda_{i} S_{i}(x, t)$

To obtain the first order sensitivity coefficients to the perturbation $\lambda_{i}$ by the DDM, the Advection-Diffusion Equation (ADE) for trace pollutants in the atmosphere:

$$
\frac{\partial c}{\partial t}+\nabla \times(u c)=\nabla \times(K \nabla c)+R+E
$$

is differentiated with respect to $\lambda_{i}$ :

$\frac{\partial S_{i}}{\partial t}+\nabla \times\left(u S_{i}\right)=\nabla \times\left(K \nabla S_{i}\right)+J S_{i}+E^{\prime}$

In Eqs. (3) and (4), $K$ is the turbulent diffusion coefficient vector, $u$ is the average horizontal wind speed considered in the advection term, $E[x, t]$ is the emission input fields and 


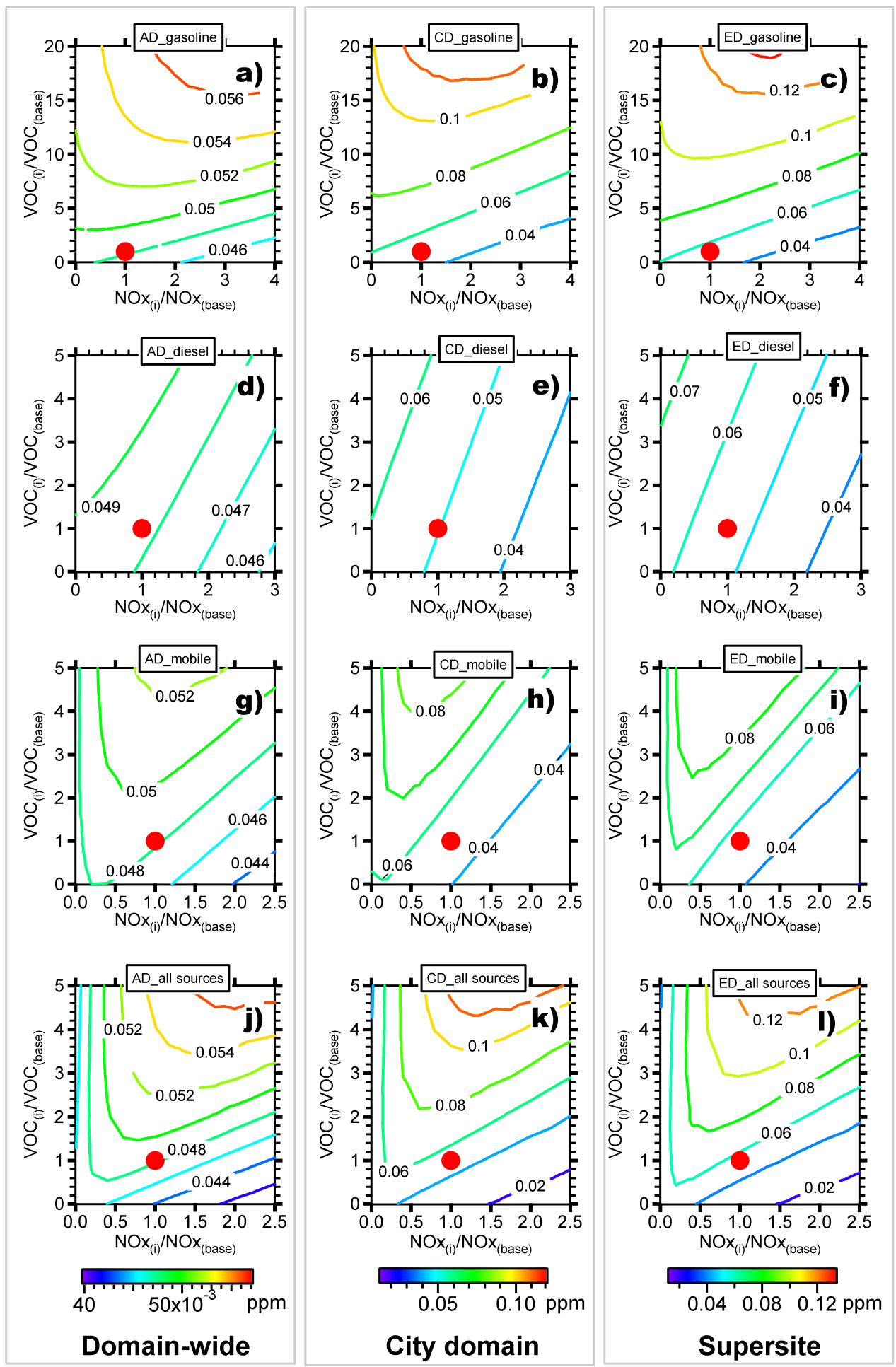

Fig. 6. Diurnal (06:00 a.m. to 06:00 p.m.) average ozone isopleths [ppm] for domain-wide (AD), city domain (CD) and supersite site (ED) for VOC and $\mathrm{NO}_{\mathrm{x}}$ emissions perturbations in gasoline $(\mathbf{a}, \mathbf{b}, \mathbf{c})$, diesel $(\mathbf{d}, \mathbf{e}, \mathbf{f})$, all mobile $(\mathbf{g}, \mathbf{h}, \mathbf{i})$, and all sources $(\mathbf{j}, \mathbf{k}, \mathbf{l})$. The axes represent mass-based scaling factors of $\mathrm{VOC}$ and $\mathrm{NO}_{\mathrm{x}}$ emissions from the base case simulation (red dot). 

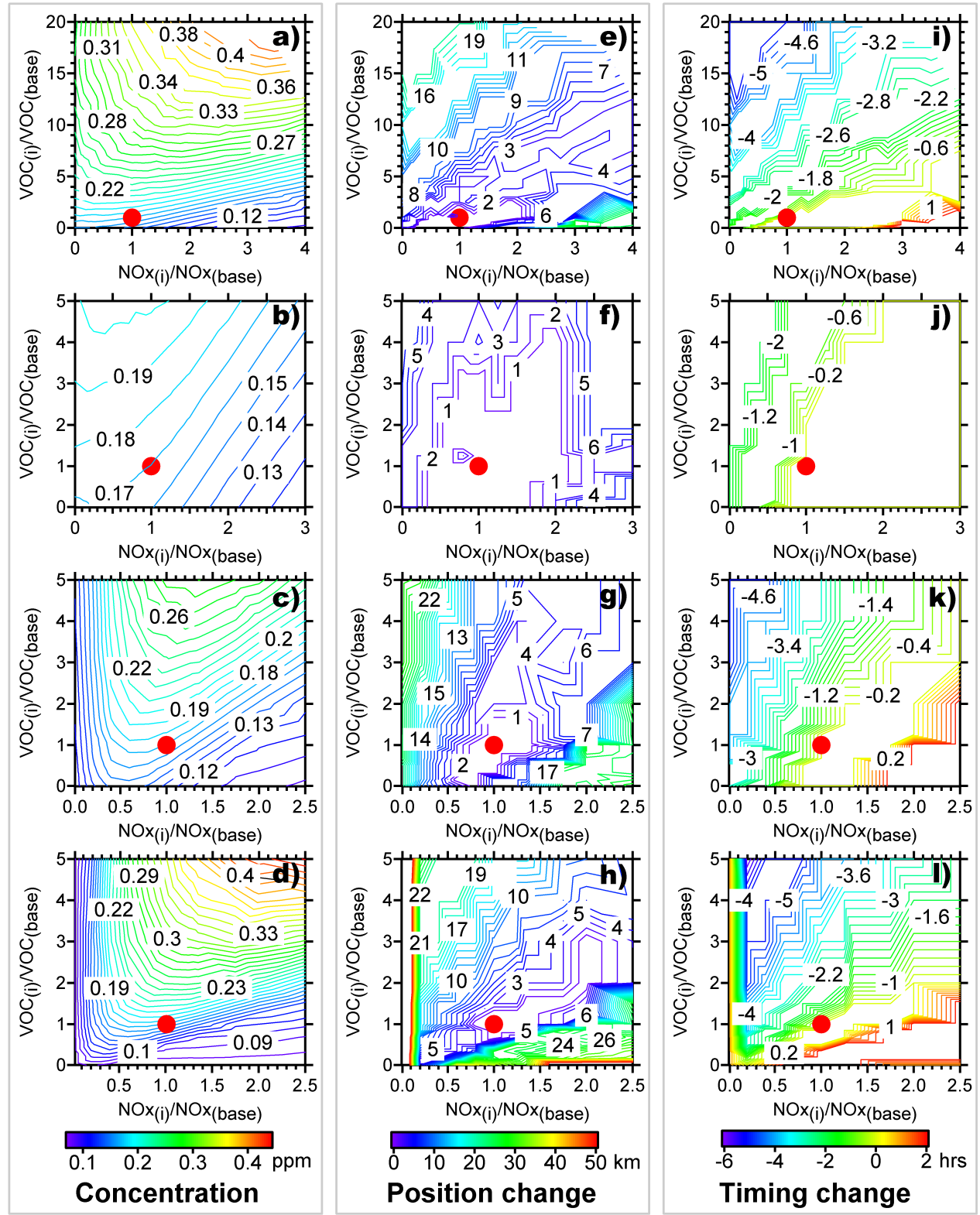

Fig. 7. Isopleths from changes in $\mathrm{VOC}$ and $\mathrm{NO}_{\mathrm{x}}$ emissions from gasoline, diesel, all mobile (gasoline + diesel), and all emission sources (biogenic + anthropogenic) for domain-wide peak ozone concentrations [ppm] (a, b, c, d), changes of the local position of the ozone peak (with respect to the base case - red dot) $[\mathrm{km}](\mathbf{e}, \mathbf{f}, \mathbf{g}, \mathbf{h})$, and changes of local timing occurrence of ozone peak (with respect to the base case) $[\mathrm{h}](\mathbf{i}, \mathbf{j}, \mathbf{k}, \mathbf{l})$.

$E^{\prime}$, denoting the differentiation of the numerical algorithm for the emission process, is the unperturbed emission rate of the sensitivity parameter. Including photolytic reactions, all chemical reactions are aggregated into the volume term $R$, whereas $J$ is the Jacobian matrix $J=(\partial R / \partial c)$ of the reaction rates. An important advantage of the DDM method is that Eqs. (3) and (4) are solved with the same spatial grid and time steps in the program's model.
Figure 8 shows the ozone sensitivity coefficients to perturbations in VOC, $\mathrm{NO}_{\mathrm{x}}$ and combined $\mathrm{VOC}$ and $\mathrm{NO}_{\mathrm{x}}$ for all emission sources obtained with the application of the DDM in CAMx for our base-case simulation. The effect on the magnitude of the ozone concentrations at first-order is given by Eq. (2) for a given perturbation level of the emissions. Similar to the results obtained with the BFM, the sensitivities depicted in Fig. 8 indicate that ozone is reduced when reductions in VOC emissions alone are implemented, while reductions in $\mathrm{NO}_{\mathrm{x}}$ emissions alone lead to ozone increases. 


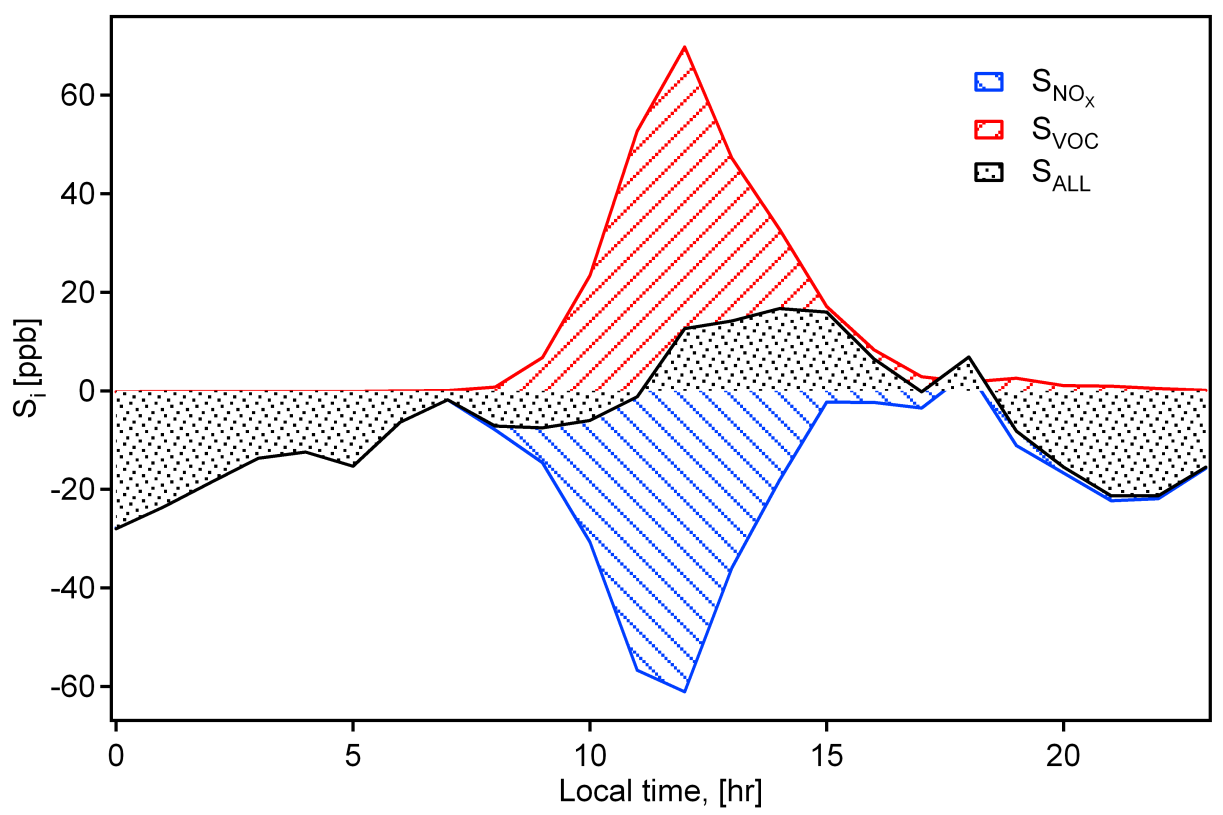

Fig. 8. City Domain (CD) sensitivity coefficients for $\mathrm{NO}_{\mathrm{x}}$, VOC and all emissions obtained using the DDM method for the perturbation of all emission sources.

Another major advantage of applying the DDM over the BFM is that the sensitivity coefficients of multiple input parameters can be estimated simultaneously during the same simulation. We obtained the sensitivity coefficients for each VOC emission group included in the VOC speciation of the SAPRC99 chemical mechanism in the model. Figure 9a indicates that ozone levels in the current base-case episode are highly sensitive to emissions of aromatics and alkenes. These two VOC groups, in addition to formaldehyde emissions, have large contributions from mobile sources (both gasoline and diesel sources), in agreement with the results from the application of the BFM. These results suggest significant benefits in ozone abatement in the city can be achieved by controlling sources that are high emitters of alkenes, aromatics and aldehydes. However, Fig. 9b also indicates that combined diesel and area sources contribute significantly to these highly reactive VOC groups, suggesting potential benefits in reducing ozone levels by controlling these emission sources.

\section{Discussion}

To discern the effects of changes of the anthropogenic emissions on the photochemical levels in an urban area is a complex task because ambient concentrations also strongly depend on meteorological conditions (e.g. Jazcilevich et al., 2005). Figure 1 shows that overall the ozone peak has been reduced significantly, but high median and maximum concentrations still persist. However, the figure also indicates that the day-to-day variability of the city-wide ozone peak is very large, even considering only the data of a couple of months each year, which indicates the large effect of daily meteorological conditions on ozone levels. Such large (but short-term) variability presupposes that properly-filtered long-term data sets have to be used for estimating the effects of changes of anthropogenic emissions on the photochemical levels.

We explored the influence of temperature variability on the observed ozone trends. The results indicate that the dailydomain-wide peak temperature variability does not have a discernible trend in the data period (not shown), suggesting that the observed trend in ozone is not influenced by the long-term variability of temperature. Short-term variability of temperature is likely to be correlated with ozone levels (warmer/cooler days versus daily ozone levels), but will not affect the results from the long-term analysis. In addition, some of the variability in the observed values during the first years may be due to differences in data acquisition protocols or problems with instrument calibration rather than to changes in the rate of the ozone formation process. Apparently, during the initial five years of its operation, the network suffered from poor quality assurance protocols for some instrumentation, which may be responsible for some of the large data variability during this period (Armando Retama, RAMA director, personal communication). After that period, the network has maintained the highest standards and quality assurance protocols.

Changes in vehicle technology and the introduction of emission control devices, as well as changes in motorization and deterioration rates, have decisively influenced the overall 

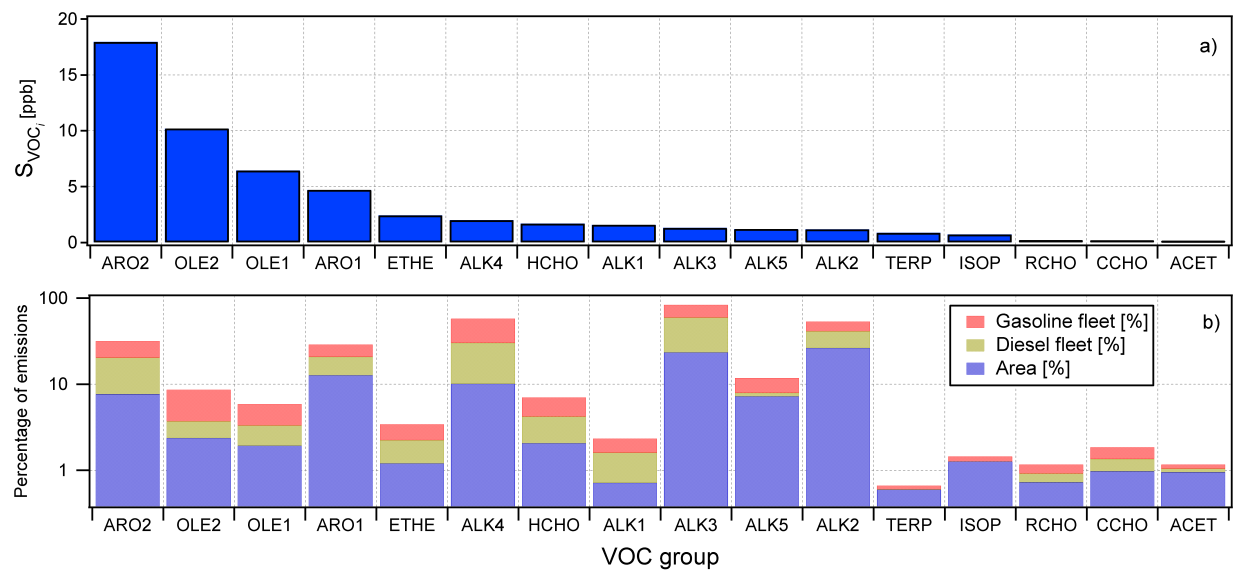

Fig. 9. Semi-normalized sensitivity coefficients for various lumped classes of VOCs according to the SAPRC $99^{a}$ chemical mechanism. ${ }^{a}$ The detailed species composition of each VOC lumped class is given elsewhere (Carter, 2000). Briefly, as the number specification of each group grows (e.g. ALK1 to ALK5), the magnitude of the rate constant of the species with OH increases. The number of individual VOC species in each group can be significant. As an approximation in molar weighting, however, we can consider that ALK1 is primarily ethane, ALK2 is primarily propane and acetylene, ALK3 is mostly n-butane and isobutane, ALK4 is mostly iso-pentane, n-pentane and 2-methyl pentane, ALK5 is a large mixture of pentanes (others than those in ALK4) to decanes, ARO1 is primarily toluene, benzene, n-propylbenzene and ethylbenzene, ARO2 is primarily m, p, and o xylenes, OLE1 are primarily terminal alkenes, OLE2 are mostly internal alkenes, CCHO are acetaldehyde and glycolaldehyde, RCHO are lumped C3+ aldehydes and TERP are biogenic alkenes other than isoprene. Explicitly emitted compounds include ETHE as ethene, HCHO (formaldehyde), ISOP as isoprene and ACET as acetone.

emission levels from mobile sources in an urban area. Other indirect factors include changes in the intensity of ridership of public transportation and traffic congestion, both linked to urban infrastructure development. A detailed description of the major air quality management programs that have been implemented since 1986 in the MCMA can be found in CAM (2002) and in Molina and Molina (2002). Some of the most relevant control policies implemented included: 1) the introduction of two-way catalytic converters for new vehicles in 1991 and three-way catalytic converters in 1993;2) the "Hoy No Circula" ("A day without a car during weekdays") program, first started in 1989 only during winter time and then continued as mandatory throughout the year; and 3) a vehicle emissions verification program that mandated the inspection and maintenance (I/M) of all vehicles twice a year. These and other control policies have significantly reduced the levels of primary pollutants, particularly those emitted from gasoline vehicles.

Measured fleet-average $\mathrm{CO}$ and $\mathrm{HC}$ emission factors show a significant decrease over time concurrently with long-term decreases of $\mathrm{CO}$ levels, indicating that technology improvements have overcome the effects of increases in fuel consumption and vehicle fleet (see Fig. 4b) on the overall CO (and likely HC) emissions. Normally, the contributions from non-combustion sources of hydrocarbons (such as painting, solvent consumption, cleaners, liquid petroleum gas (LPG) leakages, etc.) tend to increase over time as population increases. However, $\mathrm{CO}$ and $\mathrm{HC}$ emissions are both byproducts of incomplete mobile source combustion and, there- fore, the reductions in ambient concentrations of $\mathrm{CO}$ should be accompanied by reductions in ambient $\mathrm{HC}$ concentrations if non-combustion $\mathrm{HC}$ sources increase more slowly than the mobile source combustion-related emission reduction rates.

Semi-continuous canister measurements conducted between 1992 and 2001 for the C2-C12 hydrocarbons showed a slight but statistically significant decrease for that period in a small number of sites in Mexico City (Arriaga-Colina et al., 2004). However, there are no long-term continuous measurements of ambient $\mathrm{HC}$ levels in Mexico City and detailed HC information has been only obtained during intensive field campaigns. Molina and Molina (2002) and Molina et al. (2007) present a description of the major field campaigns in Mexico City. Trend assessments using the ambient levels measured in these studies would be difficult to perform due to all the intrinsic short-term variability that results from differences in the locations, time of the year (therefore different meteorological conditions), and techniques for the sampling. However, examination of the reported maximum measured concentrations in these studies shows a consistent decrease in $\mathrm{HC}$ ambient levels that is hard to explain without taking into account changes in anthropogenic emissions (Molina and Molina, 2002). More recently, measurements from the MCMA-2003 field campaign showed that vehicle exhaust is the main source of VOCs in Mexico City and that diurnal patterns strongly depend on vehicular traffic in addition to meteorological processes (Velasco et al., 2007). 
The results also suggest that overall $\mathrm{NO}_{\mathrm{x}}$ emissions from mobile sources have not experienced a constant, long term, downward trend as $\mathrm{CO}$ and $\mathrm{HCs}$ have shown in the past two decades. As noted before, there are no fleet-average $\mathrm{NO}_{\mathrm{x}}$ emission measurements available prior to 2000; it is therefore possible that there are simply not sufficient measurements in the time span of Fig. $4 \mathrm{c}$ to observe any trend in $\mathrm{NO}_{\mathrm{x}}$ emissions. However, analysis of the 06:00 to 09:00 a.m. $\mathrm{CO} / \mathrm{NO}_{\mathrm{x}}$ ratios for the 21-year period shows that the decrease has been mainly the result of reduction in CO. Additionally, individual analysis of these ratios for each monitoring station showed essentially the same behaviour suggesting that the effect is spatially homogenous.

Comparison of the variability bars in Fig. $4 \mathrm{a}$ and $\mathrm{c}$ indicates that the effect of homogenization of the vehicle fleet in its $\mathrm{CO}$ and $\mathrm{HC}$ emission characteristics is not being observed in the $\mathrm{NO}_{\mathrm{x}}$ emissions. Some possible factors that may contribute to such effect are: 1) vehicle technology, which is in turn directed by the establishment of emission standards, has been more effective in controlling $\mathrm{CO}$ and $\mathrm{HC}$ than $\mathrm{NO}_{\mathrm{x}}$ (comparison of emission standards of in-use and new vehicle, not shown, indicates that $\mathrm{CO}$ and $\mathrm{HC}$ emissions have been historically more aggressively addressed than $\mathrm{NO}_{x}$ ); 2) faster deterioration in the efficiency (shorter lifetime) of the catalytic converters for reducing $\mathrm{NO}_{\mathrm{x}}$ than for oxidizing $\mathrm{HC}$ and $\mathrm{CO}$ emissions; 3) faster growth rates of the diesel fleet than the gasoline fleet. A comparison of fuel sales data between 2000 and 2006 from the latest emissions inventory shows that gasoline fuel sales increased about $1.8 \%$ annually on average whereas diesel sales increased about $4 \%$ annually on average over that period. The greater reduction in $\mathrm{HC}$ and $\mathrm{CO}$ than for $\mathrm{NO}_{\mathrm{x}}$ is not surprising since most of the emission reduction policies and technology advancements over this time period were aimed at gasoline vehicles, which are responsible for most of the $\mathrm{CO}$ and $\mathrm{HC}$ mobile-source emissions.

Analyses of the results from the BFM indicate that for both the peak and diurnal average ozone concentrations, the shape of the ozone isopleths for each emission source category perturbed is remarkably similar among the three spatial domains studied. This suggests that a given emission control policy directed towards the reduction of ozone will be effective in both the urban area and its surroundings. The sensitivity of the model with respect to the ozone peak concentrations is larger in the $\mathrm{AD}$ (domain-wide) domain, independent of the emission source category. However, that is not the case when assessing the changes in the diurnal average concentrations, in which the model is most sensitive within the $\mathrm{CD}$ (city-wide) domain, indicating that significant benefits can be achieved simultaneously inside the city (CD domain) and outside the city (AD domain) as a result of controlling anthropogenic emissions, particularly VOCs.
The figures demonstrate that the model reproduces the corresponding relative changes in historical observations of ozone peak and diurnal average concentrations. As inferred from the historical changes of mobile emissions, the isopleths of Figs. 6 and 7 also suggest that ozone production in the MCMA has changed from a low to a currently high VOC-sensitive regime over a period of 20 years. Comparison of the isopleths between the different emission source categories also suggests that mobile-source emissions, particularly the gasoline vehicle fleet, have largely contributed to the transition.

In the current VOC-sensitive regime, the ozone concentrations are more sensitive to perturbations of all emissions others than mobile sources alone (Fig. 6). This suggests that larger benefits could be achieved with emission control policies directed to the regulation of VOC emissions from area sources along with diesel emission sources. As indicated in Table 1, solvent consumption is possibly a good candidate for such reductions given their large contribution to VOC emissions.

The isopleths of the changes of the position and local timing occurrence of the ozone peak suggest significant changes in the ozone formation rates in the city as a result of changes in anthropogenic emissions. Holding the same meteorological scenario in the model, during the transition from a low to high VOC-sensitive regime the position of the ozone peak moves significantly with respect to the base case. Considering again the illustrative perturbation of $\mathrm{VOC}_{(i)} / \mathrm{VOC}_{(\text {base })}=7$ and $\mathrm{NO}_{\mathrm{x}(\mathrm{i})} / \mathrm{NO}_{\mathrm{x}(\text { base })}=1.25$, the position of the ozone peak moved about $10 \mathrm{~km}$. An analysis of $\mathrm{x}_{(i)}$ and $\mathrm{y}_{(i)}$ indicates that such change occurred mainly southward in the model domain. Nevertheless, the magnitude and direction of this effect is merely qualitative here because the actual spatial changes in ozone formation as a result of historical changes in emissions depend on the particular meteorological conditions of every daily ozone peak event.

Similar to the BFM results, the sensitivity analyses using the DDM also indicate that ozone is reduced when reductions in VOC emissions alone are implemented and that reductions in $\mathrm{NO}_{\mathrm{x}}$ emissions alone lead to ozone increases. Simultaneous reductions of all emissions will also lead to (albeit smaller) ozone reductions only during later morning and afternoon (11:00 a.m. to 16:00 p.m.). The transition between the two regimes between 11:00 a.m. to 12:00 p.m. suggests changes on the fate of radicals and $\mathrm{NO}_{\mathrm{x}}$ in the ozone formation process. During the period from 08:00 a.m. to about 11:00 a.m. the removal of radicals may be largely dominated by the magnitude of the $\mathrm{HO}_{\mathrm{x}}-\mathrm{NO}_{\mathrm{x}}$ sink pathways (formation of $\mathrm{HNO}_{3}$, PANs, and other organic nitrates). In contrast, after midday the production of radicals would largely depend on the sources of radicals (VOC oxidation and photolysis) and the subsequent ozone formation from the $\mathrm{NO}_{2}$ photolysis dominate over the $\mathrm{HO}_{\mathrm{x}}-\mathrm{NO}_{\mathrm{x}}$ termination reactions. As the cycling of radicals during the ozone formation process depends on the specific reactivity of the air masses, both 

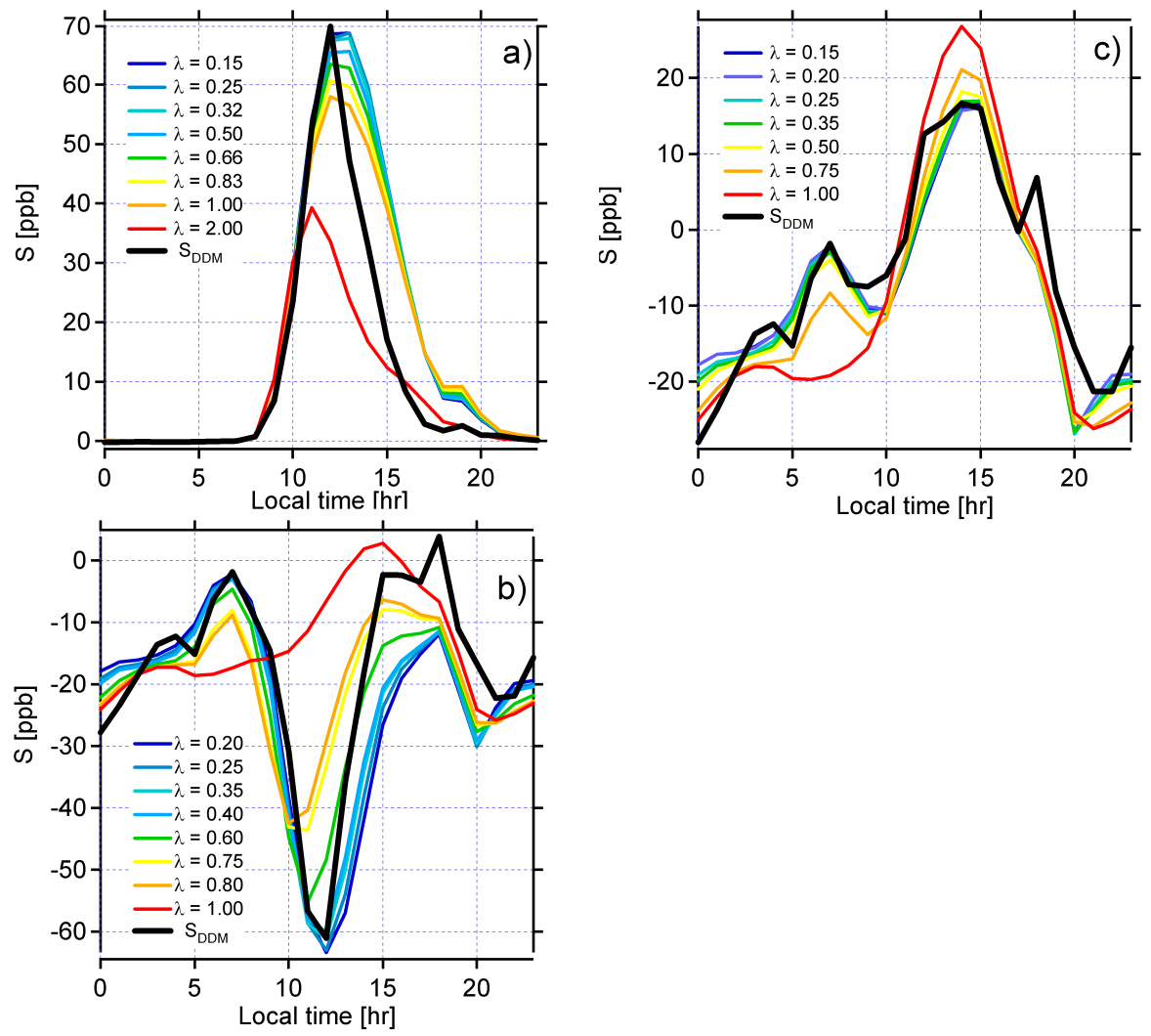

Fig. 10. Comparison of sensitivity coefficients between the DDM and the BFM methods for various magnitudes of perturbations of: (a) VOC, (b) $\mathrm{NO}_{\mathrm{x}}$, and (c) VOC and $\mathrm{NO}_{\mathrm{x}}$ emissions for all emission sources.
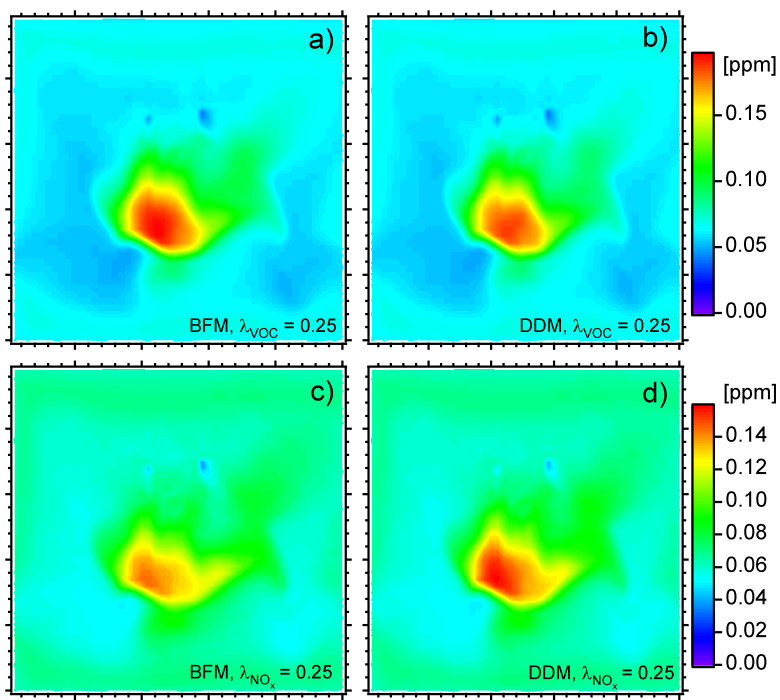

Fig. 11. Comparison of ozone concentration fields at 14:00 h, local time, obtained with the DDM and the BFM for perturbations of VOC (a and $\mathbf{b}), \mathrm{NO}_{\mathrm{x}}(\mathbf{c}$ and $\mathbf{d})$ of $\lambda=0.25$. the magnitude of the regimes and the timing of their transition observed in Fig. 8 are the results of the characteristic $\mathrm{VOC} / \mathrm{NO}_{\mathrm{x}}$ ratios of the city. Night-time ozone levels are entirely linked to $\mathrm{NO}_{\mathrm{x}}$ levels in the model as the titration pathway represents the main sink of ozone at night.

We have compared the sensitivities of the model using the $\mathrm{BFM}$ and the DDM methods for perturbations of $\mathrm{NO}_{\mathrm{x}}$, VOC and all emission sources. The comparison may be used to test the consistency of the two techniques and gives an estimate of the first order accuracy of the sensitivities provided by the DDM. For the comparison we investigated the magnitude and the temporal distributions of the sensitivity coefficients obtained by the two techniques. While Eq. (4) is used to obtain the sensitivity coefficients with the DDM, in the case of the BFM the sensitivity coefficients $S_{i}^{\mathrm{BFM}}$ are obtained by the two-side finite difference approximation:

$$
\left.S_{i}^{\mathrm{BFM}}\right|_{\lambda=0}=\frac{c(\lambda=+\delta)-c(\lambda=-\delta)}{2 \delta}=\left.\frac{\partial c}{\partial \lambda}\right|_{\lambda=0}+O\left(\delta^{2}\right)
$$

With this approximation, the quadratic dependency of $c$ on $\lambda$ cancels and the sensitivity coefficients are accurate through first-order in the perturbation $\delta$. Figure 10 shows the comparisons between the BFM and the DDM for various magnitudes of the perturbation of $\mathrm{VOC}, \mathrm{NO}_{\mathrm{x}}$ and all emission 
sources. The figure shows that the BFM sensitivities converge to the DDM sensitivities as the magnitude of the perturbation decreases in all three cases. Such convergent behaviour between the two techniques has been observed in other air quality modeling applications (e.g., Dunker et al., 2002; Hakami et al., 2003; Cohan et al., 2005). The results suggest that the model sensitivity to these emissions types behaves relatively linear for perturbations of up to $30 \%$ of the base case emissions. The model sensitivity becomes rapidly non-linear, particularly for $\mathrm{NO}_{\mathrm{x}}$ after that magnitude. The response of ozone to simultaneous perturbations of $\mathrm{NO}_{\mathrm{x}}$ and VOC emissions is more nearly linear than perturbations of any of these two alone.

Comparison of the spatial distributions of ozone concentrations predicted by the two sensitivity techniques is illustrated in Fig. 11. Whereas the spatial distribution of ozone is predicted directly in the BFM, for the DDM it was constructed using the first-order approximation (Eq. 2). Figure 11 shows that both sensitivity analyses predict similar spatial effects on ozone distribution at remarkable precision when increasing the corresponding input emission parameters by $25 \%$ from the base case. Nevertheless, there are some important differences in the magnitude of the ozone predictions. The DDM seems to predict slightly lower ozone concentrations than the BFM when considering VOC sensitivity alone. The opposite holds for $\mathrm{NO}_{\mathrm{x}}$ sensitivities: the DDM predicts higher ozone concentrations compared to the BFM. The magnitude and spatial allocation of ozone predicted by the two techniques is remarkably similar for simultaneous reductions of VOC and $\mathrm{NO}_{\mathrm{x}}$. Although the ozone spatial distributions shown in Fig. 11 were obtained only at 14:00 h local time, the effects of the model sensitivity to emission perturbations agrees with the corresponding temporal distributions comparison obtained in Fig. 10.

We note that model sensitivity studies tend to be local parametric analyses that rely on the model being structurally correct; the validity of such assumption is partially addressed (but not completely) when a thorough evaluation of the model performance is satisfactory against key simultaneously-measured chemical and meteorological parameters. Other factors such as the effects of the assumptions in the models' formulation of emission processes and the model sensitivity to meteorological and chemical parameters also affect the sensitivity of the model ozone predictions and deserve further investigation. Similarly, model sensitivities to concurrent perturbations of various VOC emission sources are not explored in this work and should be evaluated. Cross-sensitivities and higher order sensitivities (e.g. Hakami et al., 2003, 2004) and their associated uncertainties of various VOC sources are also not investigated in this work. The inclusion of second-order sensitivities in an air pollution modeling episode in the South-eastern United States provided accurate characterization of the response to large perturbations in emissions (Cohan et al., 2005). These types of sensitivities may be important when evaluating mitigation strategies that simultaneously target specific VOC emissions sources (such as solvent, paint and dry cleaning emissions, etc.), where more than one VOC emission species is affected.

\section{Conclusions}

The analyses of the concentration trends of $\mathrm{CO}, \mathrm{NO}_{\mathrm{x}}$ and ozone over the past 21 years in the MCMA show that significant changes have occurred for the variability and the diurnal temporal profiles of air pollutants in the city. The changes at night, early morning and peak concentrations are particularly evident for $\mathrm{CO}$ and ozone. Notably is the observed ozone-titration effect during the early morning that is probably linked to changes in the traffic patterns in the city as residents need to leave earlier to arrive to work on time. Overall peak ozone concentrations have been significantly reduced in the city while high median concentrations still persist. This observation is particularly important because these two metrics have very different implications when assessing the impacts of air quality management policies from the perspective of human exposure to ozone levels.

Since 1992 a reduction rate of $2.7 \pm 0.5 \mathrm{ppb} / \mathrm{yr}$ has been observed in maximum ozone concentrations after a growth rate of $12 \pm 1.3 \mathrm{ppb} / \mathrm{yr}$ from the start of the monitoring in 1986 to 1992. Using direct measurements of emissions and an indirect approach using $\mathrm{CO} / \mathrm{NO}_{\mathrm{x}}$ ratios during rush hours, we further showed that these changes are strongly linked to concurrent perturbations of anthropogenic emissions, particularly from mobile sources. Fuel-based fleet average emission factors have substantially decreased for $\mathrm{CO}$ and $\mathrm{HC}$ over the past two decades whereas $\mathrm{NO}_{\mathrm{x}}$ emission factors have not shown a strong long-term trend. Reductions in $\mathrm{CO}$ and $\mathrm{HC}$ are likely due to improvement in gasoline vehicles and emission control technologies, which are in turn related to regulatory policies and the implementation of more stringent emission standards for new and in-use vehicles.

Using the BFM, the CTM model reproduces successfully the corresponding relative changes in historical observations of ozone peak and diurnal average concentrations. This provides further evidence that ozone production in the MCMA has changed from a low to a high VOC-sensitive regime over a period of 20 years. Sensitivity analysis of the model predicts that significant benefits can be achieved simultaneously within the city and its surroundings by controlling anthropogenic emissions, particularly VOCs. Further, comparisons of the VOC and $\mathrm{NO}_{\mathrm{x}}$ sensitivities for the various emission group categories studied indicate that large benefits may be achieved also with emission control policies directed to the regulation of VOC emissions from diesel and area sources along with traditional controls of the gasoline fleet.

Comparison of the BFM and the DDM sensitivity analyses indicates that, under the base-case emission/meteorological scenario studied, the model is equally sensitive (albeit with opposite sign) to $\mathrm{NO}_{\mathrm{x}}$ and $\mathrm{VOC}$ emission reductions up to 
$30 \%$ from the base case. Beyond those perturbation levels, the sensitivity of the model is no longer linear and the accuracy of the first-order approximation decreases significantly. Using the DDM, we have modeled sensitivity coefficients to individual perturbations of VOC species lumped in groups as described by the SAPRC99 chemical mechanism. We showed that the model is particularly sensitive to aromatics, higher alkenes, and formaldehyde emissions.

Acknowledgements. The authors gratefully acknowledge the DDM subroutine for CAMx provided by Dr. G. Yarwood for the sensitivity studies in this work, the published data from the MCMA-2003 Campaign and from the Mexico City Ambient Air Quality Monitoring Network. We thank Dr. R. Slott for helpful discussion. This work was supported by the Mexican Metropolitan Commission of Environment (CAM) and the US National Science Foundation (ATM-0528227).

Edited by: C. E. Kolb

\section{References}

Altshuler, S. L., Arcado, T. D., and Lawson, D. R.: Weekday vs. weekend ambient ozone concentrations: Discussion and hypotheses with focus on northern California, J. Air Waste Ma., 45(12), 967-972, 1995.

Arriaga-Colina, J., West, J., Sosa, G., Escalona, S., Orduñez, R., and Cervantes, A.: Measurements of VOCs in Mexico City (1992-2001) and evaluation of VOCs and CO in the emissions inventory, Atmos. Environ., 38, 2523-2533, 2004.

Bishop, G. A., Stedman, D. H., Castro, J. D., and Davalos, F. J.: Onroad remote sensing of vehicle emissions in Mexico: Environ. Sci. Technol., 31, 3505-3510, 1997.

CAM (Comisión Ambiental Metropolitana): Inventario de emisiones 2004 de la Zona Metropolitana del Valle de México, Secretaría del Medio Ambiente, Gobierno de México, México, online available at: http://www.sma.df.gob.mx/, 2006.

CAM (Comision Ambiental Metropolitana): Programa para mejorar la calidad del aire en la Zona Metropolitana del Valle de México, 2002-2010, PROAIRE, online available at: http://www. sma.df.gob.mx/, 2002

Carter, W. P. L.: Documentation of the SAPRC-99 chemical mechanism for VOC reactivity, final report to California Air Resources Board, CA, Calif. Air Res. Board, Sacramento, USA, Contract 92-329 and 95-308, 2000.

Cohan, D., S., Hakami, A., Hu, Y., and Russell, A. G.: Nonlinear response of ozone to emissions: Source apportionment and sensitivity analysis, Environ. Sci. Technol., 39, 6739-6748, 2005.

de Foy, B., Caetano, E., Magana, V., Zitacuaro, A., Cardenas, B., Retama, A., Ramos, R., Molina, L. T., and Molina, M. J.: Mexico City basin wind circulation during the MCMA-2003 field campaign, Atmos. Chem. Phys., 5, 2267-2288, 2005, http://www.atmos-chem-phys.net/5/2267/2005/.

Dunker, A. M.: Efficient calculation of sensitivity coefficients for complex atmospheric models, Atmos. Environ., 15, 1155-1161, 1981.

Dunker, A. M., Yarwood, G., Ortmann, J. P., and Wilson, G. M.: The Decoupled Direct Method for sensitivity analysis in a three- dimensional air quality model-implementation, accuracy, and efficiency, Environ. Sci. Technol., 36, 2965-2976, 2002.

ENVIRON: User's guide to the comprehensive air quality model with extensions (CAMx), Version 4.31 ENVIRON Int.Corp. CA, USA, 2006.

GDF (Gobierno del Distrito Federal): Campañas de monitoreo ambiental a distancia de vehículos, Gobierno del Distrito Federal, Secretaria del Medio Ambiente, Mexico, 2006.

Grell, G. A., Dudhia, J., and Stauffer, D. R.: A Description of the fifth-generation Penn State/NCAR Mesoscale Model (MM5), NCAR/TN-398+STR., 1995.

Hakami, A., Odman, M. T., and Russell, A. G.: Nonlinearity in atmospheric response: A direct sensitivity approach, Journal of Geophysical Research, 109, D15303, doi:10.1029/2003JD004502, 2004.

Hakami, A., Odman, M. T., and Russell, A. G.: High-order, direct sensitivity analysis of multidimensional air quality models, Environ. Sci. Technol., 37, 2442-2452, 2003.

Hamby, D. M.: A review of techniques for parametric sensitivity analysis of environmental models, Environ. Monit. Assess., 32, 135-154, 1994.

Jazcilevich A., García A., and Caetano. E.: Locally induced surface air confluence by complex terrain and its effects on air pollution in the Valley of México, Atmos. Environ., 39, 5481-5489, 2005.

Lei, W., de Foy, B., Zavala, M., Volkamer, R., and Molina, L. T.: Characterizing ozone production in the Mexico City Metropolitan Area: a case study using a chemical transport model, Atmos. Chem. Phys., 7, 1347-1366, 2007, http://www.atmos-chem-phys.net/7/1347/2007/.

Lei, W., Zavala, M., de Foy, B., Volkamer, R., and Molina, L. T.: Characterizing ozone production and response under different meteorological conditions in Mexico City, Atmos. Chem. Phys. Discuss., 8, 12 053-12 079, 2008, http://www.atmos-chem-phys-discuss.net/8/12053/2008/.

Madronich, S. and Flocke, S.: The role of solar radiation in atmospheric chemistry, in: Handbook of Environmental Chemistry: Springer-Verlag, edited by: Boule, P., Heidelberg, Germany, 1998.

Molina, L. T. and Molina, M. J.: Clearing the air: a comparative study, in: Air Quality in the Mexico Megacity: An Integrated Assessment, edited by: Molina, L. T. and Molina, M. J., Kluwer Academic Publishers, Boston, 21-59, 2002.

Molina, M. J. and Molina, L. T.: Critical Review: Megacities and atmospheric pollution, J. Air Waste Ma., 54, 644-680, 2004.

Molina, L. T., Kolb, C. E., de Foy, B., Lamb, B. K., Brune, W. H., Jimenez, J. L., Ramos-Villegas, R., Sarmiento, J., ParamoFigueroa, V. H., and Cardenas, B.: Air quality in North America's most populous city, overview of the MCMA-2003 campaign, Atmos. Chem. Phys., 7, 2447-2473, 2007, http://www.atmos-chem-phys.net/7/2447/2007/.

Molina, L. T., Madronich, S., Gaffney, J. S., Singh, H. B.: Overview of MILAGRO/INTEX-B Campaign, IGAC Newsletter, Issue No. 38, 2-15, April 2008.

Mugica, V., Vega, E., Arriaga, J. L., and Ruiz, M. E.: Determination of motor vehicle profiles for non-methane organic compounds in the Mexico City metropolitan area: J. Air Waste Ma., 48, 10601068, 1998.

Napelenok, S. L., Cohan, D., Hu, Y., and Russell, A. G.: Decoupled direct 3-D sensitivity analysis for particulate matter (DDM- 
3-D/PM), Atmos. Environ., 40 (32), 6112-6121, 2006.

NRC (National Research Council): Rethinking the ozone problem in urban and regional air pollution, National Academy Press, Washington, DC, USA, 163-186, 1991.

Schifter, I., Diaz, L., Duran, J., Guzman, E., Chavez, O., and LopezSalinas, E.: Remote sensing study of emissions from motor vehicles in the metropolitan area of Mexico City, Environ. Sci. Technol., 37, 395-401, 2003a.

Schifter, I., Diaz, L., Vera, M., Guzman, E., Duran, J., Ramos, F., and Lopez-Salinas, E.: Evaluation of the vehicle inspection/maintenance program in the Metropolitan Area of Mexico City: Environ. Sci. Technol., 37, 196-200, 2003b.

Seinfeld, J. H. and Pandis, S. N.: Atmospheric chemistry and physics: from air pollution to climate change, A WileyInterscience publication, USA, 235-309, 1998.

Shaw, W. J., Pekour, M. S., Coulter, R. L., Martin, T. J., and Walters, J. T.: The daytime mixing layer observed by radiosonde, profiler, and lidar during MILAGRO, Atmos. Chem. Phys. Discuss., 7, 15 025-15 065, 2007, http://www.atmos-chem-phys-discuss.net/7/15025/2007/.

Stephens, S., Madronich, S., Wu, F., Olson, J., Ramos, R., Retama, A., and Munoz, R.: Weekly patterns of Mexico City'is surface concentrations of $\mathrm{CO}, \mathrm{NO}_{\mathrm{x}}, \mathrm{PM}_{10}$ and $\mathrm{O}_{3}$ during 1986-2007, Atmos. Chem. Phys., 8, 5313-5125, 2008,

http://www.atmos-chem-phys.net/8/5313/2008/.
Velasco, E., Lamb, B., Westberg, H., Allwine, E., Sosa, G., ArriagaColina, J. L., Jobson, B. T., Alexander, M. L., Prazeller, P., Knighton, W. B., Rogers, T. M., Grutter, M., Herndon, S. C., Kolb, C. E., Zavala, M., de Foy, B., Volkamer, R., Molina, L. T., and Molina, M. J.: Distribution, magnitudes, reactivities, ratios and diurnal patterns of volatile organic compounds in the Valley of Mexico during the MCMA 2002 and 2003 field campaigns, Atmos. Chem. Phys., 7, 329-353, 2007, http://www.atmos-chem-phys.net/7/329/2007/.

Volkamer, R., Zavala, M., Molina, L., Molina, M., Flores, E., Grutter, M., Samuelsson, J., Mellqvist, J., Galle, B., and Knighton, B.: Open-path emission factors derived from DOAS and FTIR measurements in the Mexico City Metropolitan Area. Poster contribution to Air Pollution as a Climate Forcing: A second Workshop, Honolulu, Hawaii, 4-6 April 2005.

Yang, Y. J., Wilkinson, J. G., and Russell, A. G.: Fast, direct sensitivity analysis of multidimensional photochemical models, Environ. Sci. Technol., 31, 2859-2868, 1997.

Yarwood, G., Morris, R. E., and Wilson, G. M.: Particulate matter source apportionment technology (PSAT) in the CAMx photochemical grid model, Proceedings from the International Technical Meeting, Banff, Canada, October, 2004.

Zavala, M., Herndon, S. C., Slott, R. S., Dunlea, E. J., Marr, L. C., Shorter, J. H., Zahniser, M., Knighton, W. B., Rogers, T. M., Kolb, C. E., Molina, L. T., and Molina, M. J.: Characterization of on-road vehicle emissions in the Mexico City Metropolitan Area using a mobile laboratory in chase and fleet average measurement modes during the MCMA-2003 field campaign, Atmos. Chem. Phys., 6, 5129-5142., 2006. 